\title{
RFID-tagged amazonian stingless bees confirm that landscape configuration and nest re-establishment time affect homing ability
}

\author{
L. Costa $^{1}$ (D) P. Nunes-Silva ${ }^{2}$ - J. S. Galaschi-Teixeira ${ }^{1} \cdot$ H. Arruda ${ }^{2} \cdot$ J. C. Veiga ${ }^{1} \cdot$ G. Pessin ${ }^{3} \cdot$ P. de Souza ${ }^{4}$. \\ V. L. Imperatriz-Fonseca ${ }^{1,5}$
}

Received: 16 June 2020 / Revised: 18 November 2020 / Accepted: 2 December 2020 / Published online: 4 February 2021

(c) The Author(s) 2021

\begin{abstract}
Bee flight capacity determines the area that a colony can exploit, and this knowledge is essential to formulate management and conservation strategies for each species. In this study, we evaluated the flight capacity of Melipona seminigra using radio frequency identification (RFID). Three questions were addressed: Do the RFID tags affect the flight of $M$. seminigra workers? What is the effect of the landscape on foraging activity? Does the time since the colony was re-established affect the flight range of foragers? Our results indicate that the RFID tag used does not affect the flight ability of M. seminigra. Bees marked with nontoxic paint vs. RFID tags had the same return ratio and return time to the colony of origin. Flight capacity was affected by the landscape, because the return rate to the colonies was higher from the tested vegetated area than from the sterile area. The time elapsed since the bee colony re-establishment also affected the flight range because the return rate increased with time since the colony was relocated in the new site. We estimate that $M$. seminigra workers make foraging flights of approximately $1000 \mathrm{~m}$ from the colony and that the maximum flight range is $5000 \mathrm{~m}$. Colonies of this species take more than 1 or 2 months to be able to fully exploit a landscape.
\end{abstract}

Keywords Flight range $\cdot$ Meliponiculture $\cdot$ Meliponini $\cdot$ Apidae $\cdot$ Honey $\cdot$ Pollination $\cdot$ Apiculture

\section{Introduction}

The colony is the center of the world of social bees, and workers leave it to go on foraging trips that can extend a few kilometers from their home (Capaldi and Dyer 1999; Nunes-Silva et al. 2019; Pahl et al. 2011; Rodrigues and Ribeiro 2014; Smith et al. 2017). The flight capacity of bees is related to body size (Greenleaf et al. 2007) and body measurements, such as head width (Nieuwstadt and Iraheta

L. Costa

costa.luciano@itv.org; costaluc33@gmail.com

1 Instituto Tecnológico Vale, Sustainable Development, ITVDS, Belém, Pará, Brazil

2 University of Vale do Rio dos Sinos, UNISINOS, São Leopoldo, Rio Grande do Sul, Brazil

3 Instituto Tecnológico Vale, Mining, ITVMI, Ouro Preto, Minas Gerais, Brazil

4 School of Information and Communication Technology, Griffith University, Gold Coast, Queensland 4222, Australia

5 Biosciences Institute, University of São Paulo, São Paulo, São Paulo, Brazil
1996), thorax width, and wing size (Araújo et al. 2004), which are good predictors of flight capacity, even within the same species (Kuhn-Neto et al. 2009).

In addition to body size, the flight range of bees is related to the ability to locate the nest in the landscape, called homing ability. This ability depends on the integration of memory with different sensory systems, such as magnetic field perception, sight, and smell (Chittka et al. 1999; Heinze 2017; Menzel et al. 2006, 1998). Some factors may influence the functioning of the homing ability of bees, such as experience (Capaldi and Dyer 1999; He et al. 2013; Rodrigues and Ribeiro 2014) and environmental factors, for example, the presence and type of landmarks (Leonhardt et al. 2016; Southwick and Buchmann 1995), pesticide contamination (Stanley et al. 2016), diseases (Bordier et al. 2017; Li et al. 2013; Wolf et al. 2014), and pests (Kralj and Fuchs 2006).

The flight capacity of bees determines the area they can explore (Gathmann et al. 1994; Walther-Hellwig and Frankl 2000a, b; Wright et al. 2015), so the resources they need to survive and reproduce, such as pollen, nectar, nesting sites, and reproductive partners, must be present in this area. Therefore, determining the flight capacity of a bee species 
is fundamental to understanding its ecology and, based on this, formulating appropriate strategies for species management, for either conservation or production purposes (mainly honey and pollination) (Dramstad et al. 2003; Gathmann and Tscharntke 2002; Guédot et al. 2009; Nieuwstadt and Iraheta 1996; Wright et al. 2015).

The stingless bee Melipona seminigra is found throughout most of the Amazon biome (Camargo 1994). Due to its wide occurrence and ecological characteristics, it is one of the native bees that is most reared in the region by subsistence farmers and hobbyists (Carvalho-Zilse et al. 2005; Venturieri 2008; Venturieri et al. 2012). Seven geographic variations are recognized for this species, with the pernigra variety found between the Tapajós River and northwest Maranhão state to the middle and low Tocantins and Xingu basins (Camargo 1994). In the Carajás National Forest region, the native variety is Melipona seminigra pernigra (Costa 2019).

The overall objective of this study was to evaluate the foraging flight distance and maximum flight distance (maximum homing ability) of colonies of M. seminigra pernigra using the automated data collection method of radio frequency identification (RFID). Three questions were addressed: (1) do the RFID tags used for monitoring affect the flight of $M$. seminigra? (2) What is the effect of the landscape on the flight activity of $M$. seminigra? (3) Does experience (measured as time since colony re-establishment in the area) affect the flight range of $M$. seminigra? Our hypotheses were as follows: (1) the RFID tags used for monitoring would not affect the flight of $M$. seminigra. (2) A landscape without floral resources would not attract foragers, so they would not know this area, decreasing the rate of return and increasing the time required for return to the colony from such an area. (3) Colonies long established in the area, which were therefore more experienced, would have higher flight capacity (higher rates of return and in less time) than colonies newly established in the area, as already observed in Apis mellifera (He et al. 2013).

\section{Material and methods}

\section{Study site}

The flight capacity evaluation experiments were conducted between July and August 2017 at Carajás National Forest, Brazil (6ㅇ 5' 17.93" S; 50 9' $0.30 " \mathrm{~W}$; approximately $700 \mathrm{~m}$ altitude) (Ministério do Meio Ambiente and ICMBio 2016). Carajás National Forest is located in the Amazon biome, and its vegetation is mainly open rainforest, dense rainforest, and canga (metallophyte savanna or ferruginous fields) (Ministério do Meio Ambiente and ICMBio 2016). The landscape around the site where the experimental colonies were set up had two contrasting environments: an open area without vegetation (mining crater) and a rainforest with canga areas (Fig. 1). The climate in Carajás is AWi under the Köppen classification (Alvares et al. 2013). July and August are the driest months, with an abundance of flowering plants during this period. All experimental days were sunny and had temperatures between 25 and $32{ }^{\circ} \mathrm{C}$.

\section{Colonies used in the experiments}

Colonies of Melipona seminigra under similar developmental conditions, i.e., equivalent numbers/amounts of brood combs, foragers, and stored food, were used in all experiments. All colonies were housed in rearing boxes commonly used for rearing Melipona fasciculata (Venturieri 2004) that contained a brood chamber filled with brood combs and honey and pollen pots, in addition to a full honey super. To perform experiment 1 , we used colonies with the same time since establishment at the site, for experiment 2 , we used only one of the colonies; and for experiment 3 , we used colonies with different times since re-establishment at the study site.

\section{Preparation of the bees for the experiments and RFID monitoring system}

To affix the tags, we collected the workers that returned with pollen, resins, or clay or that had a dilated abdomen (full of nectar), directly at the entrance of the colony. The tag was fixed on the dorsum of the bees using high-viscosity cyanoacrylate glue (TekBond, Saint-Gobain). The identification tags used were passive RFID transponders operating in the ultrahigh-frequency band of $860-920 \mathrm{MHz}$ (Hitachi Chemical, Tokyo). Each tag measured $2.5 \times 2.5 \times 0.3 \mathrm{~mm}$ and weighed $5.4 \mathrm{mg}$ (1/13th of M. seminigra's weight: $70 \mathrm{mg}$ ) (Fig. 1a). The tag size fitted easily in the $2.9 \mathrm{~mm}$ wide intertegular region of $M$. seminigra worker, without disturbing the wings. After affixing the tags, the workers remained in a dark box with access to a $50 \%$ solution sucrose ad libitum until they were released. We collected the foragers in the morning (between approximately 8:00 and 9:00 a.m.) and released them at noon. The releases began at the largest distances and ended at the smallest distances. To monitor bee return, on the front of the wooden bee boxes we placed modified plastic boxes (Fig. 2) containing the RFID reader equipment: an antenna (RFID detector) and a computer (reader and data recorder-Intel Edison) [details in (Gomes et al. 2020) and (Nunes-Silva et al. 2019)]. This RFID reading system allowed us to take multiple readings of the same bee as it passed over the antenna (Fig. 2), 

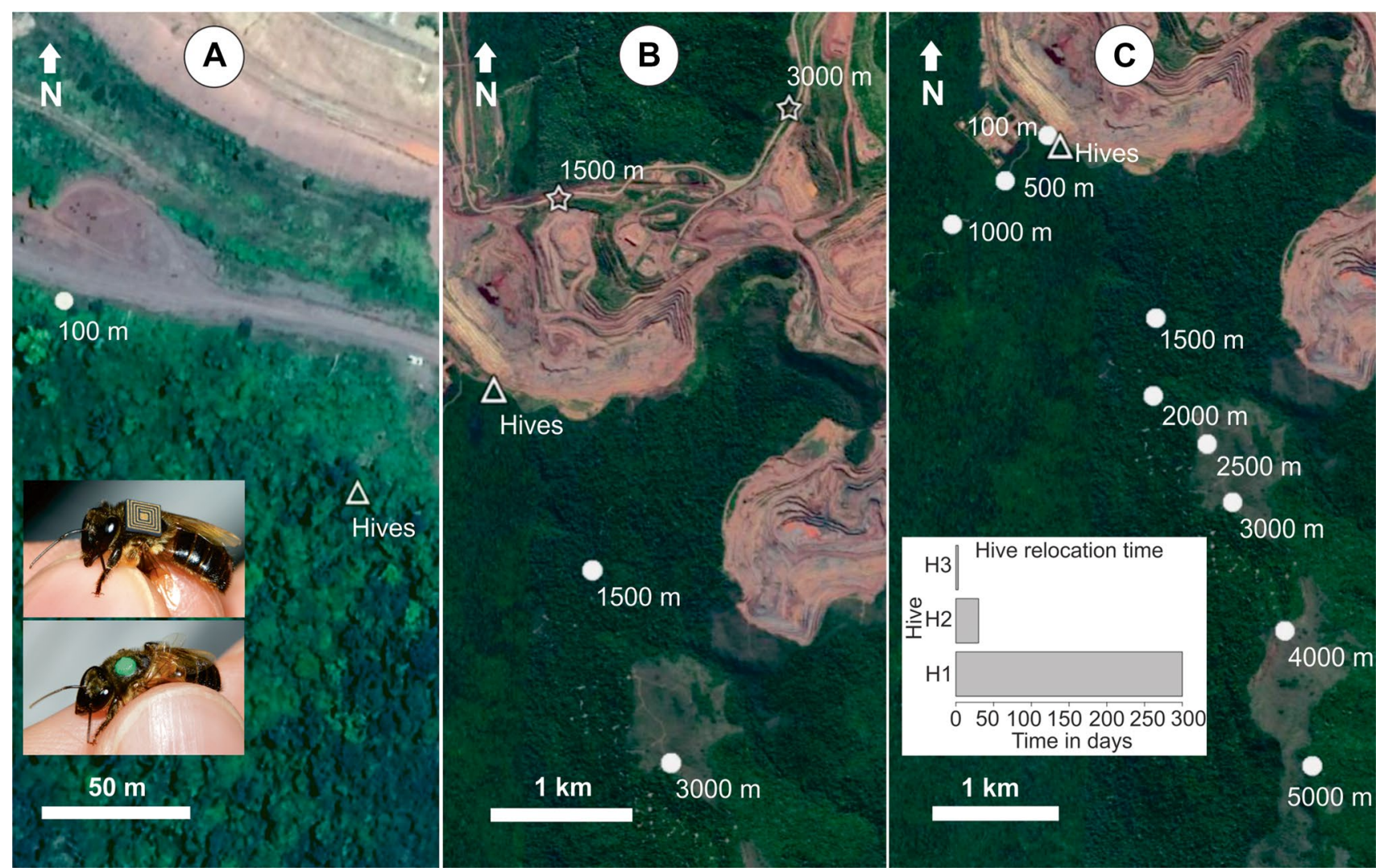

Fig. 1 Maps showing the release points of the three experiments conducted at Carajás National Forest. a Experiment 1. Melipona seminigra workers were marked with RFID tags or nontoxic paint. b Experiment 2. Points marked with a star represent the distances tested through the area without vegetation (mine); points marked with white

avoiding misreadings, as shown in Apis mellifera (Susanto et al. 2018).

\section{Experiment 1}

Experiment 1 consisted of an evaluation of the effect of the tag glued to the thorax on the flight capacity of M. seminigra. We conducted this evaluation because this species is $2 \mathrm{~mm}$ smaller than $M$. fasciculata, the species in which we tested these sensors for the first time (Costa 2019; NunesSilva et al. 2019). We translocated and released groups of 30 bees (from each of the three experimental colonies) at a distance of $100 \mathrm{~m}$. We used the same number of bees affixed with tags and marked with nontoxic paint (Fig. 1a). The return of bees marked with different colors of paint was determined visually by three observers, each positioned in front of one of the experimental colonies, for $3 \mathrm{~h}$. The same observation time was used as a cutoff for the return of RFID tagged bees, which were automatically counted. circles represent the same distances tested through the area with native vegetation. $\mathbf{c}$ Experiment 3 . Nine release points tested to measure the flight capacity of $M$. seminigra foragers from colonies with different times since establishment at the study site (white box)

\section{Experiment 2}

Experiment 2 evaluated the effect of landscape on the flight activity of $M$. seminigra. Once the experimental colonies were set up in the forest flanking the mining area, we sought to assess whether the wide-open area of the mine located northward (Fig. 1b) constituted a barrier to the flight activity of $M$. seminigra. For this, we chose two release points to the north on the other side of the mine cavity. The smallest distance to cross the mine was $1500 \mathrm{~m}$ and the longest distance to cross the mine was $3000 \mathrm{~m}$. These points were compared with two points of equal distance to the south (the same points used in experiment 3 , in a natural landscape). Thirty foraging workers were tagged and translocated for release at each point (i.e., 120 tagged workers in total). For this experiment, we used only one of the colonies (H1), since the other two colonies were replaced for experiment 3. 
Fig. 2 a Front view of the bee hive (Venturieri 2004) equipped with the RFID reading system. b Side view of the hive equipped with the RFID reading system. c Top view showing the RFID reading system and access of the bees to the nest. Each hive module measures $25 \times 25 \times 8 \mathrm{~cm}$
A

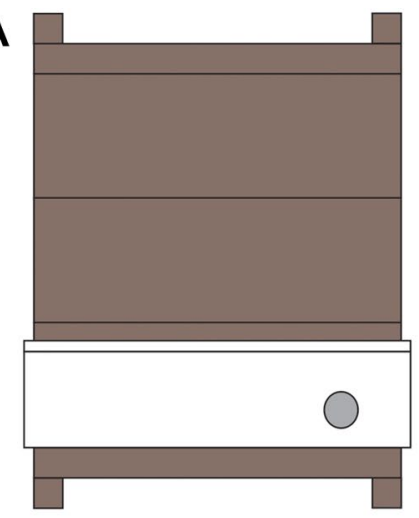

B

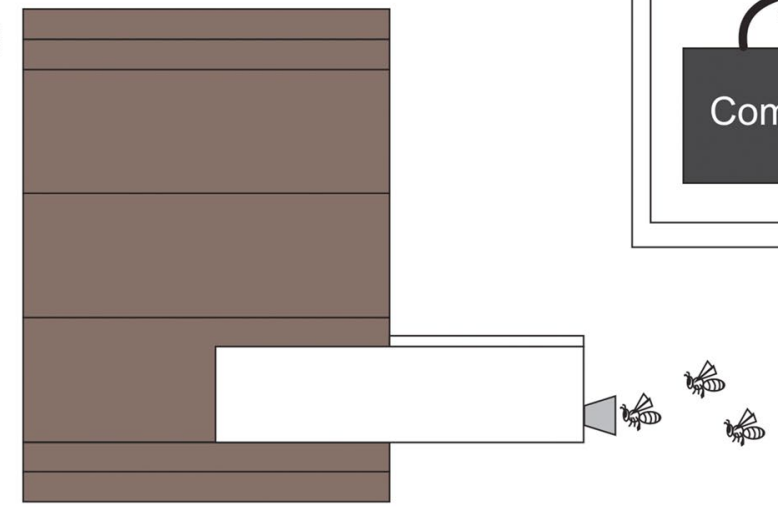

C

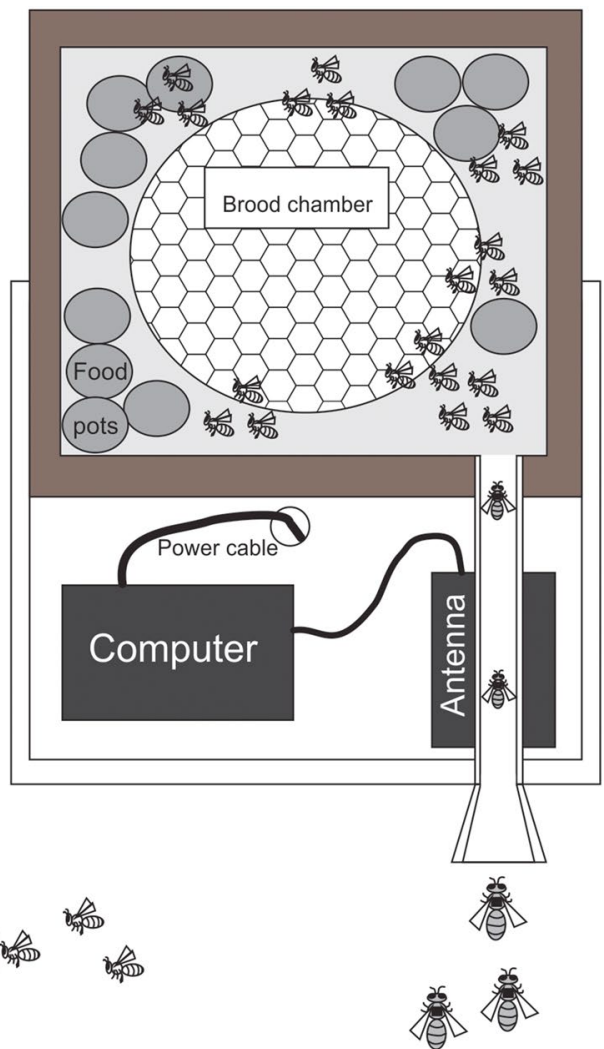

\section{Experiment 3}

Experiment 3 evaluated the maximum homing ability and foraging range (or flight range). With this objective, nine distances were set up to determine the flight capacity of $M$. seminigra: $100 \mathrm{~m}, 500 \mathrm{~m}, 1000 \mathrm{~m}, 1500 \mathrm{~m}, 2000 \mathrm{~m}, 2500 \mathrm{~m}$, $3000 \mathrm{~m}, 4000 \mathrm{~m}$, and $5000 \mathrm{~m}$ (Fig. 1c). The experimental colonies were ground zero. Thirty bees from each colony were tagged and released at each of the nine experimental distances (i.e., 810 tagged workers in total). We took forage workers from three colonies of $M$. seminigra, named $\mathrm{H} 1$ (the same as in experiments 1 and 2), $\mathrm{H} 2$, and $\mathrm{H} 3$. The first colony (H1) was placed at the experimental site 10 months before the start of the experiment. The second (H2) was brought to the experimental site 1 month before the start, and the third (H3) was brought to the experimental site 3 days before the start.

\section{Statistical analysis}

The return, or homing, rate was estimated by the number of workers who made their way back home, regardless of the time required. To calculate the return time, the time of release and take-off of the bees was considered the starting time, and the time of entry into the colony was the ending time. Flight time was therefore calculated as the difference between the ending and starting times.
The return rate and return time data were evaluated for homogeneity of variance with Bartlett's test. The normality of the data was evaluated with the Shapiro-Wilk test. As the data were not normal, comparisons between groups (different distances) were performed using the Wilcoxon and Kruskal-Wallis tests, as appropriate. In experiment 1, we used the Pearson Chi-squared $\left(\chi^{2}\right)$ test for return rate comparisons and the Wilcoxon test for return time comparisons under the different treatments. In experiment 2 , we used the Pearson $\chi^{2}$ test for return rate comparisons and the Wilcoxon test for return time analyses. In experiment 3 , we analyzed the data from the three colonies separately to compare the colonies with different setup times at the study site. To evaluate homing ability, we considered the total number of workers that returned from the different tested distances, i.e., the return rate, within 5 days. The foraging range (or flight range) was estimated by the return time, considering only the workers that returned on the same day of release, assuming that these workers were the most experienced and therefore the most informative for estimating the foraging range. Post hoc analysis was performed using pairwise test for multiple comparisons of mean rank-sum (Nemenyi Test). The analyses were performed with the $\mathrm{R}$ programming language ( $\mathrm{R}$ Core Team 2017) within R Studio software (RStudio Team 2015). 


\section{Results}

\section{Experiment 1}

The return rate of the foragers marked with the electronic tag $(n=18)$ was not different from that of the workers marked with paint $(n=28)\left(\chi^{2}=2.18, d f=1, p=0.14\right)$. Similarly, the return time of the workers marked with the different treatments did not differ according to analysis of variance $(W=177, p=0.09)$. The fastest bee was marked with an RFID tag and made the return trip in $4.28 \mathrm{~min}$, which equaled a speed of $0.4 \mathrm{~m} / \mathrm{s}$. Among the bees marked with paint, the fastest one made the trip in 6 min, equivalent to a speed of $0.3 \mathrm{~m} / \mathrm{s}$.

\section{Experiment 2}

There was a significant difference in the number of bees that returned from the north (other side of the mine cavity) vs. from the south (forest) from the distance of $1500 \mathrm{~m}$ $\left(\chi^{2}=3.86, d f=1, p=0.05\right)$. Half $(50 \%, n=15)$ of the bees released at a distance of $1500 \mathrm{~m}$ in the south direction returned, while only $20 \%(n=6)$ of the bees managed to return from the north direction (on the other side of the mine). However, there was no significant difference in the return rates for the $3000 \mathrm{~m}$ distance $\left(\chi^{2}=1, d f=1, p=0.32\right)$. Only $6.7 \%(n=3)$ of the workers returned from $3000 \mathrm{~m}$ from the forest direction (south), while 3.3\% $(n=1)$ returned from the other side of the mine in the north direction. The return times of the bees released at the $1500 \mathrm{~m}$ distance did not differ significantly ( $W=54, p=0.52$ ) between forest (south) and mine (north). The fastest bee made this trip from the forest (distance of $1500 \mathrm{~m}$ ) at $0.13 \mathrm{~m} / \mathrm{s}$, and the fastest bee released on the mine side (distance of $1500 \mathrm{~m}$ ) made the trip in $0.10 \mathrm{~m} / \mathrm{s}$.

\section{Experiment 3}

The return ability was not the same between all the tested colonies (Fig. 3). It was more similar between colonies H1 and $\mathrm{H} 2(W=46.5, p=0.62)$, but there was a trend for fewer workers to return from colony $\mathrm{H} 3$ than $\mathrm{H} 1$, but the results were above the significant threshold $(W=60.5, p=0.08)$. The highest return ability was from colony $\mathrm{H} 1$, of which one worker (3\%) returned from $5000 \mathrm{~m}$, followed by colony $\mathrm{H} 2$, of which one worker (3\%) returned from $4000 \mathrm{~m}$. The return limit for workers of colony $\mathrm{H} 3$ was $2000 \mathrm{~m}$, from which only one worker (3\%) returned.

The return rate was greater than $50 \%$ up to $1000 \mathrm{~m}$ (Fig. 3) for colonies $\mathrm{H} 1$ and $\mathrm{H} 2$. At $\geq 1500 \mathrm{~m}$, there was a decrease in the return rate to $50 \%(\mathrm{H} 1)$ or lower $(\mathrm{H} 2)$. At $\geq 2000 \mathrm{~m}$, only $20 \%$ or fewer (H3) of the workers returned. Less than $50 \%$ of the bees returned to $\mathrm{H} 3$ from all release distances.

Return times for $\mathrm{H} 1$ differed significantly between release distances $\left(K-W \chi^{2}=24.833, d f=3, p=1.674 \mathrm{e}-05\right)$. Nemenyi's post hoc test revealed significant differences between 100 and $1500 \mathrm{~m}(p=1.5 \mathrm{e}-05)$ and between 500 and $1500 \mathrm{~m}$ $(p=0.00)$. Therefore, there was a significant increase in the return time of Melipona seminigra workers released at $\geq 1500 \mathrm{~m}$ (Fig. 4). The fastest bee returned from $100 \mathrm{~m}$ in $1.13 \mathrm{~min}$, which made for a speed of $1.5 \mathrm{~m} / \mathrm{s}$.
Fig. 3 Numbers of Melipona seminigra workers from colonies $\mathrm{H} 1, \mathrm{H} 2$, and $\mathrm{H} 3$ that returned from each of the tested distances. Thirty workers (from each colony) were marked with RFID tags and released at each distance. The dotted line represents $50 \%$ return

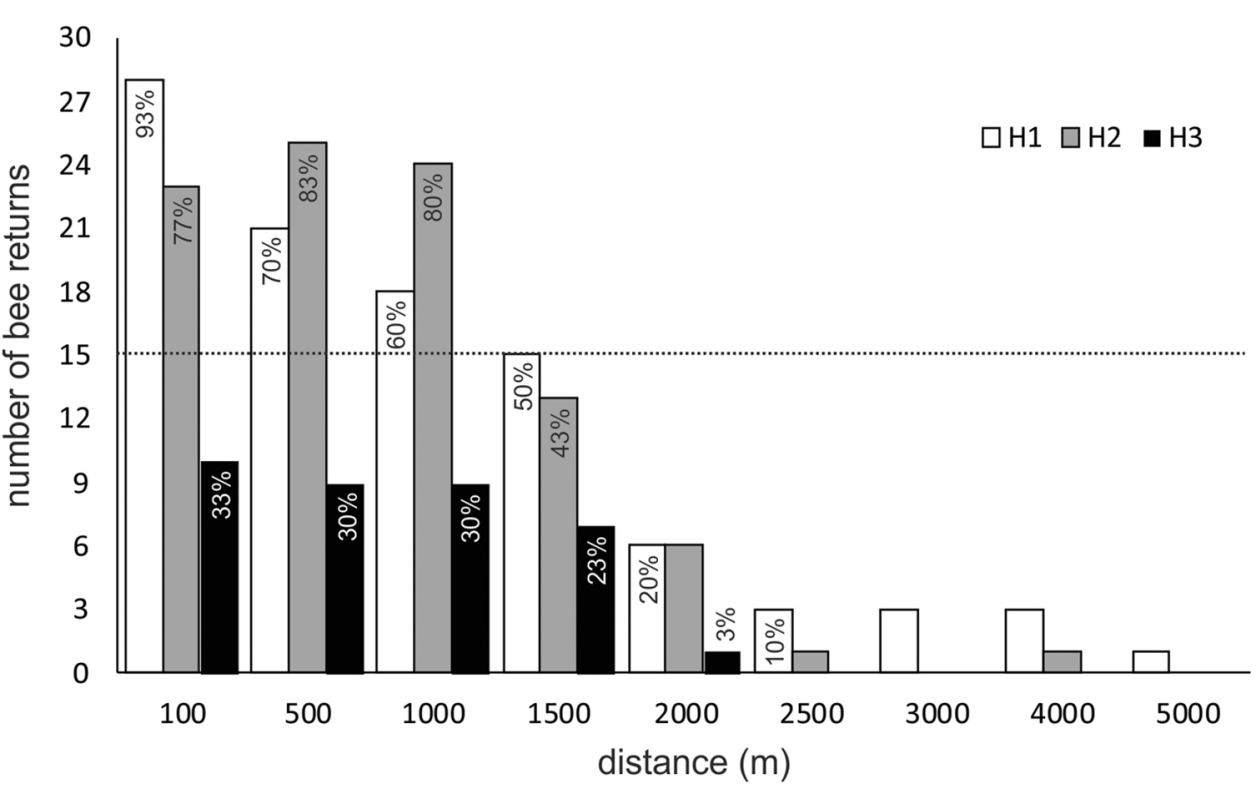




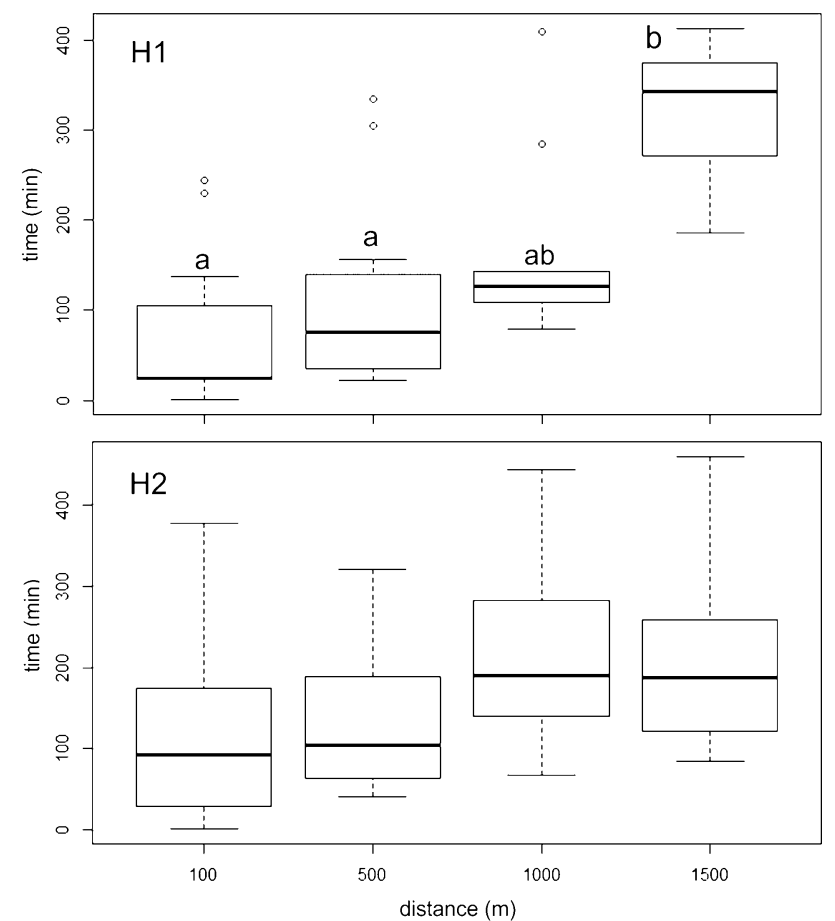

Fig. 4 Top: return time for workers released at different distances, colony H1. Distances above $1500 \mathrm{~m}$ were not included in the analysis. Only one worker returned from $2000 \mathrm{~m}$ to the $\mathrm{H} 1$ colony on the first experimental day. Kruskal-Wallis $\chi^{2}=24.833, d f=3, p=1.674 \mathrm{e}-05$. Bottom: box plot showing the return times for workers released at different distances, colony $\mathrm{H} 2$. Although differences were found by the Kruskal-Wallis test (KW $\chi^{2}=10.795, d f=4, p=0.03$ ), Nemenyi's post hoc test indicated no significant differences in return time with release distance $(p>0.26)$. In this figure, each box indicates the 25 th75th percentiles, the black line inside the box indicates the median, the dashed lines indicate the minimum and maximum limits, and the circles indicate the outliers. Number of bee returns per distance and colony: $100 \mathrm{~m}(\mathrm{H} 1=13 ; \mathrm{H} 2=17) ; 500 \mathrm{~m}(\mathrm{H} 1$ and $\mathrm{H} 2=17) ; 1000 \mathrm{~m}$ $(\mathrm{H} 1=10 ; \mathrm{H} 2=11) ; 1500 \mathrm{~m}(\mathrm{H} 1=10 ; \mathrm{H} 2=6)$

\section{Discussion}

The use of RFID monitoring in the study of bee behavior is relatively recent and has been applied to species with relatively large body sizes (Nunes-Silva et al. 2018). Our comparison between RFID tags and paint indicated that M. seminigra is not hampered in its flight capacity by tag use. Both the return rate and the return time did not differ between the workers marked with electronic tags and those marked with paint. The same was observed in other studies using RFID tags in different species of bees (He et al. 2013; Nunes-Silva et al. 2019, 2018; Oystaeyen et al. 2013), confirming that RFID monitoring is a technique with great potential.

Landscape-related factors, such as the landmarks that bees learn and use for orientation when returning to the nest, influence the flight distance and the homing ability of bees (Southwick and Buchmann 1995; Steffan-Dewenter and Kuhn 2003). Apis mellifera, for example, shows different homing abilities when released in different directions, demonstrating that the area of activity is not circular but rather is motivated by landscape elements, which allow them to learn the landscape (Pahl et al. 2011). Another component is resource availability (Campbell et al. 2019; Garbuzov and Ratnieks 2014; Southwick and Buchmann 1995). Thus, because the return rate was higher for the bees released in the direction of the forest (south side) than for bees released at the same distance in the mining area, we conclude that the landscape has an effect on the flight capacity of M. semini$\mathrm{gra}$, as observed in other bee species. It is possible that, due to the lack of resources in the sterile mining environment, the M. seminigra workers were not familiar with the release site and therefore were unable to return from there to the colony.

Based on the return rates in experiment 3, we estimated that the distance at which the M. seminigra workers forage is approximately $1000 \mathrm{~m}$. Up to this distance, more than $60 \%$ of the workers can return to the colony of origin. At $\geq 1500 \mathrm{~m}, 50 \%$ or fewer of the bees could return home. There was a sharp drop in the number of bees that returned to the colonies at $\geq 2000 \mathrm{~m}$, from which the return rate dropped to $20 \%$ or less. The numbers of bees that returned to colonies $\mathrm{H} 1$ and $\mathrm{H} 2$ were similar, but they contrasted with the few bees that returned to colony H3. The maximum homing ability also differed between the colonies, being higher in $\mathrm{H} 1$ (5000 m) than in H2 (4000 m) and H3 (2000 m). The analysis of return times for the different distances resulted in significant differences only for the $\mathrm{H} 1$ colony, with no differences for colonies $\mathrm{H} 2$ and $\mathrm{H} 3$. The return times of $\mathrm{H} 1$ workers increased significantly starting at $1500 \mathrm{~m}$. Colony $\mathrm{H} 1$ was at the experimental site for 10 months, colony $\mathrm{H} 2$ for 1 month, and colony $\mathrm{H} 3$ for 3 days before the beginning of the experiment. Colony H1, the longest established, had a flight time proportional to the distance, as the bees took longer when they started farther than when they started closer to the colony. Colony $\mathrm{H} 2$ and colony $\mathrm{H} 3$, in particular, showed greater variation in return times at all distances tested (Fig. 4), probably due to the greater number of disoriented bees, which took longer to return even at shorter distances. These results indicate the influence of colony experience (time in a given area) on the return capacity of M. seminigra workers, as observed for Apis mellifera (He et al. 2013) and Melipona mandacaia (Rodrigues and Ribeiro 2014).

Thus, we conclude that $M$. seminigra workers make foraging flights of approximately $1000 \mathrm{~m}$, with $5000 \mathrm{~m}$ being the maximum homing capacity for this species. These distances represent half the flight capacity estimated for M. fasciculata using the same equipment as the present study and in the same environment (Nunes-Silva et al. 2019). Melipona seminigra has a body size approximately $2 \mathrm{~mm}$ smaller than 
M. fasciculata (Costa 2019), and the intertegular distance of M. seminigra is $2.9 \mathrm{~mm}, 0.4 \mathrm{~mm}$ smaller than the $3.3 \mathrm{~mm}$ of M. fasciculata (Borges et al. 2020). Thus, this result corroborates previous studies that show a correlation between body size and flight capacity of Meliponini species (Araújo et al. 2004; Greenleaf et al. 2007; Mayes et al. 2019; Nieuwstadt and Iraheta 1996).

The mapping of landmarks and resources in the landscape is important for a bee's ability to exploit the environment. This result indicates that in changing landscapes, such as deforestation areas, or seasonal changes in soil used for agriculture, bees in the remaining natural areas might have trouble in orientation, and consequently impact their ability to forage and survive. Moreover, colonies that have been at a site less than 2 months do not have workers that can fully exploit a new landscape, as observed in Apis mellifera (He et al. 2013). This information should be considered when using these bees for pollination of agricultural crops, as well as for the conservation of colonies transferred from one location to another. We recommend that colonies newly established in a new location receive special care, such as supplementary feeding, for at least 1 or 2 months.

Acknowledgements We thank Serra Norte and Serra Sul Environmental Management-Vale's North Corridor Operations Directorate-especially Leonardo Grandiski Neves, Sérgio de Souza Júnior, Fábia Cavalcante Pinho, Renan Coelho, Olegário Reis, Jenaldo Carvalho, Luiz Batista, Lourival Tyski, Delmo Silva, Alexandre Castilho, Leandro Maioli, and Cesar Carvalho Neto-for their support with field activities. We also would like to thank Daniela Zappi for the English revision of this manuscript. This study was funded by Conselho Nacional de Desenvolvimento Científico e Tecnológico (Grant number 152393/2016-6 and 380430/2017-7) and Instituto Tecnológico Vale.

Funding This research was supported by Instituto Tecnológico Vale and CNPq.

Data availability The analyzed data is available, if necessary.

\section{Compliance with ethical standards}

Conflict of interest There are no conflicts.

Ethics approval This study was conducted in accordance with Brazilian environmental laws.

Consent to participate All authors agreed to participate in this manuscript.

Consent for publication All authors agreed to submit this manuscript for publication.

Open Access This article is licensed under a Creative Commons Attribution 4.0 International License, which permits use, sharing, adaptation, distribution and reproduction in any medium or format, as long as you give appropriate credit to the original author(s) and the source, provide a link to the Creative Commons licence, and indicate if changes were made. The images or other third party material in this article are included in the article's Creative Commons licence, unless indicated otherwise in a credit line to the material. If material is not included in the article's Creative Commons licence and your intended use is not permitted by statutory regulation or exceeds the permitted use, you will need to obtain permission directly from the copyright holder. To view a copy of this licence, visit http://creativecommons.org/licenses/by/4.0/.

\section{References}

Alvares CA, Stape JL, Sentelhas PC et al (2013) Köppen's climate classification map for Brazil. Meteorol Zeitschrift 22:711-728. https://doi.org/10.1127/0941-2948/2013/0507

Araújo ED, Costa M, Chaud-Netto J, Fowler HG (2004) Body size and flight distance in stingless bees (Hymenoptera: Meliponini): inference of flight range and possible ecological implications. Braz J Biol 64:563-568. https://doi.org/10.1590/S1519-69842 004000400003

Bordier C, Pioz M, Crauser D et al (2017) Should I stay or should I go: honeybee drifting behaviour as a function of parasitism. Apidologie 48:286-297. https://doi.org/10.1007/s13592-016-0475-1

Borges RC, Padovani K, Imperatriz-fonseca VL, Giannini TC (2020) A dataset of multi-functional ecological traits of Brazilian bees. Sci Data 7:1-9. https://doi.org/10.1038/s41597-020-0461-3

Camargo JMF (1994) Biogeografia de Meliponini (Hymenoptera, Apidae, Apinae): a fauna Amazônica. Anais do Encontro Sobre Abelhas. Faculdade de Filosofia, Ribeirão Preto, pp 46-59

Campbell AJ, Gomes RLC, da Silva KC, Contrera FAL (2019) Temporal variation in homing ability of the neotropical stingless bee Scaptotrigona aff. postica (Hymenoptera: Apidae: Meliponini). Apidologie 50:720-732. https://doi.org/10.1007/s13592-01900682-z

Capaldi EA, Dyer FC (1999) The role of orientation flights on homing performance in honeybees. J Exp Biol 202:1655-1666

Carvalho-Zilse GA, Silva CGN, Zilse N et al (2005) Criação de abelhas sem ferrão. Istituto Brasileiro de Meio Ambiente e Recursos Naturais Renováveis, Brasília

Chittka L, Williams NM, Rasmussen H, Thomson JD (1999) Navigation without vision: bumblebee orientation in complete darkness. Proc R Soc B Biol Sci 266:45-50. https://doi.org/10.1098/ rspb.1999.0602

Costa L (2019) Guia Fotográrfico de Identificação de Abelhas Sem Ferrão, para resgate em áreas de supressão florestal. Instituto Tecnológico Vale, Belém

Dramstad WE, Fry GLA, Schaffer MJ (2003) Bumblebee foraging-is closer really better? Agric Ecosyst Environ 95:349-357. https:// doi.org/10.1016/S0167-8809(02)00043-9

Garbuzov M, Ratnieks FLW (2014) Quantifying variation among garden plants in attractiveness to bees and other flower-visiting insects. Funct Ecol 28:364-374. https://doi. org/10.1111/1365-2435.12178

Gathmann A, Tscharntke T (2002) Foraging ranges of solitary bees. J Anim Ecol 71:757-764. https://doi.org/10.104 6/j.1365-2656.2002.00641.x

Gathmann A, Greiler H-J, Tscharntke T (1994) Trap-nesting bees and wasps colonizing set-aside fields: succession and body size, management by cutting and sowing. Oecologia 98:8-14. https://doi. org/10.1007/BF00326084

Gomes PAB, Suhara Y, Nunes-silva P et al (2020) An Amazon stingless bee foraging activity predicted using recurrent artificial neural networks and attribute selection. Sci Rep 10:1-12. https://doi. org/10.1038/s41598-019-56352-8 
Greenleaf SS, Williams NM, Winfree R, Kremen C (2007) Bee foraging ranges and their relationship to body size. Oecologia 153:589596. https://doi.org/10.1007/s00442-007-0752-9

Guédot C, Bosch J, Kemp WP (2009) Relationship between body size and homing ability in the genus Osmia (Hymenoptera; Megachilidae). Ecol Entomol 34:158-161. https://doi.org/10.111 1/j.1365-2311.2008.01054.x

He X, Wang W, Qin Q et al (2013) Assessment of flight activity and homing ability in Asian and European honey bee species, Apis cerana and Apis mellifera, measured with radio frequency tags. Apidologie 44:38-51. https://doi.org/10.1007/s13592-012-0156-7

Heinze S (2017) Unraveling the neural basis of insect navigation. Curr Opin Insect Sci 24:58-67. https://doi.org/10.1016/j. cois.2017.09.001

Kralj J, Fuchs S (2006) Parasitic Varroa destructor mites influence flight duration and homing ability of infested Apis mellifera foragers. Apidologie 37:577-587. https://doi.org/10.1051/apido:20060 40

Kuhn-Neto B, Contrera FAL, Castro MS, Nieh JC (2009) Long distance foraging and recruitment by a stingless bee, Melipona mandacaia. Apidologie 40:472-480. https://doi.org/10.1051/apido/2009007

Leonhardt SD, Kaluza BF, Wallace H, Heard TA (2016) Resources or landmarks: which factors drive homing success in Tetragonula carbonaria foraging in natural and disturbed landscapes? J Comp Physiol A Neuroethol Sens Neural Behav Physiol 202:701-708. https://doi.org/10.1007/s00359-016-1100-5

Li Z, Chen Y, Zhang S et al (2013) Viral infection affects sucrose responsiveness and homing ability of forager honey bees, Apis mellifera L. PLoS ONE 8:e77354. https://doi.org/10.1371/journ al.pone.0077354

Mayes DM, Bhatta CP, Shi D, Brown JC, Smith DR (2019) Body size influences stingless bee (Hymenoptera: Apidae) communities across a range of deforestation levels in Rondônia, Brazil. J Insect Sci. https://doi.org/10.1093/jisesa/iez032

Menzel R, Geiger K, Joerges J et al (1998) Bees travel novel homeward routes by integrating separately acquired vector memories. Anim Behav 55:139-152

Menzel R, De Marco RJ, Greggers U (2006) Spatial memory, navigation and dance behaviour in Apis mellifera. J Comp Physiol A Neuroethol Sens Neural Behav Physiol 192:889-903

Nunes-Silva P, Hrncir M, Guimarães JTF et al (2018) Applications of RFID technology on the study of bees. Insectes Soc. https://doi. org/10.1007/s00040-018-0660-5

Nunes-Silva P, Costa L, Campbell AJ et al (2019) Radiofrequency identification (RFID) reveals long-distance flight and homing abilities of the stingless bee Melipona fasciculata. Apidologie. https://doi.org/10.1007/s13592-019-00706-8

Pahl M, Zhu H, Tautz J, Zhang S (2011) Large scale homing in honeybees. PLoS ONE 6:1-7. https://doi.org/10.1371/journ al.pone.0019669

R Core Team (2017) R: a language and environment for statistical computing. R Foundation for Statistical Computing, Vienna, Austria. http://www.R-project.org/

Rodrigues F, Ribeiro MF (2014) Influence of experience on homing ability of foragers of Melipona mandacaia Smith (Hymenoptera:
Apidae: Meliponini). Sociobiology 61:523-528. https://doi. org/10.13102/sociobiology.v61i4.523-528

RStudio Team (2015) RStudio: integrated development environment for R, Boston, MA. http://www.rstudio.com/

Smith JP, Heard TA, Beekman M, Gloag R (2017) Flight range of the Australian stingless bee Tetragonula carbonaria (Hymenoptera: Apidae). Austral Entomol 56:50-53. https://doi.org/10.1111/ aen.12206

Southwick EE, Buchmann SL (1995) Effects of horizon landmarks on homing success in honey bees. Am Nat 146:748-764. https://doi. org/10.1086/285823

Stanley DA, Russell AL, Morrison SJ et al (2016) Investigating the impacts of field-realistic exposure to a neonicotinoid pesticide on bumblebee foraging, homing ability and colony growth. J Appl Ecol 53:1440-1449. https://doi.org/10.1111/1365-2664.12689

Steffan-Dewenter I, Kuhn A (2003) Honeybee foraging in differentially structured landscapes. Proc Biol Sci 270:569-575. https:// doi.org/10.1098/rspb.2002.2292

Susanto F, Gillard T, De Souza P et al (2018) Addressing RFID misreadings to better infer bee hive activity. IEEE Access 6:3193531949. https://doi.org/10.1109/ACCESS.2018.2844181

van Nieuwstadt M, Iraheta C (1996) Relation between size and foraging range in stingless bees (Apidae, Meliponinae). Apidologie 27:219-228. https://doi.org/10.1051/apido:19960404

Van Oystaeyen A, Alves DA, Oliveira RC et al (2013) Sneaky queens in Melipona bees selectively detect and infiltrate queenless colonies. Anim Behav 86:603-609. https://doi.org/10.1016/j.anbeh av.2013.07.001

Venturieri GC (2004) Meliponicultura I: Caixa Racional de Criação. Comun Técnico Embrapa 123:1-3

Venturieri GC (2008) Criação racional de meliponíneos: uma alternativa econômica entre os agricultores familiares amazônicos. Apacame Mensagem Doce 69:1-4

Venturieri GC, Alves DA, Menezes C et al (2012) Meliponicultura no Brasil: Situação Atual e Perspectivas Futuras para o Uso na Polinização Agrícola. In: Imperatriz-Fonseca VL, Canhos DAL, Alves DA, Saraiva AM (eds) Polinizadores no Brasil. Editora da Universidade de São Paulo, São Paulo, pp 213-236

Walther-Hellwig K, Frankl R (2000a) Foraging habitats and foraging distances of bumblebees, Bombus spp. (Hym., Apidae), in an agricultural landscape. J Appl Entomol 124:299-306. https://doi. org/10.1046/j.1439-0418.2000.00484.x

Walther-Hellwig K, Frankl R (2000b) Foraging distances of Bombus muscorum, Bombus lapidarius, and Bombus terrestris (Hymenoptera, Apidae). J Insect Behav 13:239-246. https://doi. org/10.1023/A:1007740315207

Wolf S, McMahon DP, Lim KS et al (2014) So Near and yet so far: harmonic radar reveals reduced homing ability of nosema infected honeybees. PLoS ONE 9:e103989. https://doi.org/10.1371/journ al.pone. 0103989

Wright IR, Roberts SPM, Collins BE (2015) Evidence of forage distance limitations for small bees (Hymenoptera: Apidae). Eur J Entomol 112:303-310. https://doi.org/10.14411/eje.2015.028 